\title{
Galantamine treatment in Alzheimer's disease: response and long-term outcome in a routine clinical setting
}

This article was published in the following Dove Press journal:

Neuropsychiatric Disease and Treatment

29 September 2011

Number of times this article has been viewed

\section{Åsa K Wallin \\ Carina Wattmo \\ Lennart Minthon}

Clinical Memory Research Unit, Department of Clinical Sciences, Lund University, Malmö, Sweden
Correspondence: Åsa K Wallin Neuropsychiatric Clinic, Skåne University Hospital, SE-205 02 Malmö, Sweden

$\mathrm{Tel}+4640335036$

Fax +46 40335657

Email asa.k.wallin@skane.se
Background: In the absence of long-term, placebo-controlled studies of cholinesterase inhibitors in Alzheimer's disease (AD), analysis of the results of open-label trials becomes crucial. This study aimed to explore the three-year effects of galantamine treatment, as well as subgroups of response and adherence to treatment.

Methods: Two hundred and eighty patients with a clinical diagnosis of AD were included in the prospective, open-label, multicenter Swedish Alzheimer Treatment Study, and received galantamine treatment. Efficacy measures included cognitive tests, ie, the Mini-Mental State Examination (MMSE) and Alzheimer's Disease Assessment Scale Cognitive Subscale (ADAS-cog), functional rating (Instrumental Activities of Daily Living Scale [IADL]), and global rating. Assessments were carried out before treatment and every six months for a period of three years. K-means cluster analysis was used to identify response subgroups.

Results: After three years of treatment, the mean change from baseline was 2.6 points in MMSE and 5.6 points in ADAS-cog scores. Globally, half of the patients improved or remained unchanged for two years. Cluster analysis identified two response clusters. Cluster 1 included patients with low ability in ADAS-cog and IADL scores at baseline. Even though the patients in cluster 1 were older and less educated, they responded better at six months compared with patients in cluster 2. Cluster 2 included patients with better ADAS-cog and IADL scores at baseline. Patients in cluster 2 had a higher frequency of the $A P O E \varepsilon 4$ allele, a slower pretreatment progression rate, and remained in the study longer than those in cluster 1 . Three-year completers ( $\mathrm{n}=129,46 \%$ ) received higher doses of galantamine compared with dropouts.

Conclusion: AD patients who received long-term galantamine treatment were cognitively and globally stabilized. Subgroup response analysis identified a better short-term response in older patients with lower cognitive and functional abilities at baseline, a faster pretreatment progression rate, and a lower incidence of the $A P O E \varepsilon 4$ allele. The galantamine dose was higher in the population of completers.

Keywords: Alzheimer's disease, long-term treatment, routine setting, cholinesterase inhibitor, galantamine, k-means cluster analysis, completion rates

\section{Introduction}

Alzheimer's disease (AD) is the major cause of dementia, and underlies more than $60 \%$ of dementia cases. ${ }^{1}$ The incidence and prevalence of AD increase with age. ${ }^{2}$ Reports of increasing life expectancy in developed countries ${ }^{3}$ indicate that $\mathrm{AD}$ will be one of the biggest health care challenges in the future. Without treatment, AD is characterized by a progressive and irreversible decline in cognitive and practical abilities, leading to major difficulties after only a few years of disease duration. ${ }^{4}$ 
In the 1990s, cholinesterase inhibitors (ChEIs) became the first drugs used to treat the symptoms of AD. ChEIs, which work by counteracting cholinergic deficits, and memantine, which inhibits glutamate overexpression, continue to be the drugs available for the treatment of $\mathrm{AD} .^{5}$ The second-generation ChEIs include donepezil, rivastigmine, and galantamine. Galantamine, which is a competitive and rapidly reversible inhibitor of acetylcholinesterase and an allosteric modulator of nicotine receptors, ${ }^{6}$ gained approval in Sweden in 2000. Multiple double-blind, placebo-controlled clinical trials showed the beneficial effects of galantamine treatment on the cognitive and behavioral symptoms in $\mathrm{AD}$ patients for up to six months. ${ }^{7-9}$ Because ethical constraints prohibit the use of long-term, placebo-controlled studies of ChEIs in $\mathrm{AD}$, the analysis of results from open-label, longterm trials is important.

The response to ChEI varies within the AD population. Multiple factors have been outlined that enhance response to ChEI treatment in $\mathrm{AD} ;{ }^{10}$ however, there are no standard guidelines that define response to treatment. To overcome this issue, data-driven techniques, such as cluster analysis, could be used to investigate natural subgroups of $\mathrm{AD}$ populations in treatment studies. ${ }^{11}$ Low completion rates are another difficulty of long-term studies of AD patients, both with or without treatment. Three-year completion rates range between $4 \%$ and $39 \%,{ }^{12-19}$ making it difficult to comprehend fully the long-term outcomes of treatment in AD. The investigation of treatment dropout and the search for methods aimed at enhancing completion rates and adherence to treatment are warranted in the field of AD research.

The Swedish Alzheimer Treatment Study was designed to evaluate the long-term effects of ChEI treatment in a routine clinical setting. Data obtained from patients treated with donepezil and rivastigmine were reported previously. ${ }^{20,21}$ The clinical outcome of and adherence to long-term galantamine treatment in a routine setting remain to be investigated.

In this report, we investigated the first 280 patients who received galantamine in the Swedish Alzheimer Treatment Study program; these individuals were recruited until the end of 2005 and had the opportunity to participate for three years. The aims of this report are to describe the cognitive (Mini-Mental State Examination [MMSE] and Alzheimer's Disease Assessment Scale Cognitive Subscale [ADAS-cog]), functional (Instrumental Activities of Daily Living Scale [IADL]), and global outcomes of treatment, to identify treatment subgroups, and to investigate the rates of dropout and adherence to treatment.

\section{Materials and methods}

\section{Subjects}

Two hundred and eighty patients were recruited prospectively from 10 centers. The study data were collected by participating physicians at memory clinics across Sweden. The workup at baseline included medical history, informant-based information, physical and neurological examination, extended cognitive testing, laboratory tests, and computed tomography or magnetic resonance imaging of the brain. In some centers, patients were investigated additionally using cerebrospinal fluid taps, APOE genotyping, measurements of regional cerebral blood flow (SPECT), electroencephalography, and neuropsychological testing; however, these were not criteria for inclusion. Patients fulfilled the clinical criteria of dementia, as defined by the Diagnostic and Statistical Manual of Mental Disorders, Fourth Edition (DSM-IV), ${ }^{22}$ and of probable or possible $\mathrm{AD}$, according to the criteria of the National Institute of Neurological and Communicative Disorders and Stroke and the Alzheimer's Disease and Related Disorders Association. ${ }^{23}$

The inclusion criteria were wide, and included $\mathrm{AD}$ patients aged older than 40 years, living at home at the time of diagnosis, having a caregiver, assessable via MMSE at baseline, and able to give their informed consent to participate in the study. Patients who did not fulfill the diagnostic criteria for $\mathrm{AD}$ and those already receiving active treatment with another $\mathrm{ChEI}$ or with contraindications to galantamine treatment were excluded from the study. The decision to start the patient on ChEI was made by the treating physician, in accordance with the standards used in routine clinical practice.

Medication other than antidementia drugs was allowed during the study. Concomitant medications and their doses were recorded. If other dementia treatments (ie, memantine or study drugs) were added, patients left the study at that point.

All participating centers were trained in Good Clinical Practice, in diagnostics, and in the uniform use of the rating scales applied in this study. The data from the different centers were collected prospectively and the results were sent continuously to the Memory Research Unit in Malmö for monitoring and data handling. The study was approved by the ethics committee of the University of Lund. All patients and their closest relative/caregiver provided written informed consent to participate in the study, which was carried out in accordance with the Declaration of Helsinki.

\section{Study design and outcome measures}

Cognitive assessment was performed using the $\mathrm{MMSE}^{24}$ and ADAS-cog (0-70). ${ }^{25}$ MMSE scores range from 0 to 30 , 
with a higher score indicating better function. Scores on the ADAS-cog version range from 0 to 70 , with a higher score indicating lower function. ADAS-cog responses of patients at the different time intervals were investigated using the following cutoffs of change: "improved", 4 or more points of improvement; "unchanged", 3 to -3 points; and "worse", 4 or more points of deterioration.

Functional status was measured using the IADL scale, ${ }^{26}$ which ranges from 8 to 31 points, with a higher value indicating more impaired function. The eight items on the IADL scale were telephone use, shopping, food preparation, housekeeping, laundry, transportation, medication, and finances. If an item was not applicable to the individual, its score was 0 . Disease level at baseline was assessed using a seven-point scale (from " 1 = normal" to " 7 = very severe"). ${ }^{27}$ The Clinician's InterviewBased Impression of Change (CIBIC) rating ${ }^{28,29}$ was used as a global measure of "change from baseline". The CIBIC uses a seven-point scale (from " 1 = very much improved" to " 7 = very much worse"), with a score of 4 indicating no change from baseline. No guidelines or descriptors were provided to define the individual ratings. Global rating was meant to measure the overall improvement, regardless of patient score on cognitive tests. Patients could be regarded as being globally better but still score less well on the cognitive tests. The distinction between minimally improved or much improved was left to the clinical judgment of the individual rater.

Baseline was defined as the assessment prior to the first dose of treatment. All patients assessed at baseline and treated with at least one dose of galantamine were included in the outcome analysis (observed cases). The assessments at baseline were performed before and close to the start of ChEI treatment. Patients were assessed for all outcome measures at baseline and every six months after the baseline assessment for a period of three years. In addition, MMSE and global rating were performed at the two-month visit.

\section{Comparative analysis}

The Stern equation was used to calculate the annual change in ADAS-cog score if the patients had not been treated. ${ }^{30}$ This equation is based on the ADAS- $\operatorname{cog}(0-70)$ of $A D$ patients with a baseline ADAS-cog score in the range of 5-69 points.

The Stern equation is as follows:

Predicted ADAS-cog score at a time T

$$
\begin{aligned}
= & -6.039689+1.329485 \mathrm{x}_{\mathrm{i}}-0.005392 \mathrm{x}_{\mathrm{i}}^{2}+(0.031974 \\
& \left.+0.036652 \mathrm{x}_{\mathrm{i}}-0.000473634 \mathrm{x}_{\mathrm{i}}^{2}\right) \mathrm{T}
\end{aligned}
$$

where $\mathrm{T}$ is time from baseline and $\mathrm{x}_{\mathrm{i}}$ is baseline ADAS-cog score for an individual. The ADAS-cog value predicted using the Stern equation was calculated for each individual at each interval of the study. The mean change in ADAS-cog score from baseline was obtained based on these calculations. These scores were used as mathematical controls.

The annual decrease in MMSE score in untreated AD patients was estimated at 2-4 points per year, and the annual increase in ADAS-cog was estimated at 4-9 points per year, based on historical reports of annualized decline. ${ }^{30-33}$

\section{Subgroup analysis}

A cluster analysis was applied to investigate the possibility of identifying natural subgroups of clinically sensible patients (short-term response). Patient baseline values of IADL and ADAS-cog and their six-month rate of change were used as variables in the analysis. The analysis included only patients with complete data at six months.

The subgroups identified were described and compared. Differences in age, gender, duration of illness, number of years of education, $A P O E$ genotype (presence or absence of the $A P O E \& 4$ allele), number and type of medications at baseline, galantamine dose, occurrence of dropout, MMSE level at baseline, and pretreatment progression rate in MMSE were investigated. Pretreatment progression rate was calculated using the following formula: 30-baseline MMSE/estimated duration of symptoms in years, as described previously. ${ }^{34}$

\section{Treatment}

After inclusion and baseline assessments, patients received galantamine treatment according to the approved product labeling, as in routine clinical practice. Patients were initially prescribed tablets, but when the extended-release capsules became available, patients switched to this formulation. All patients were started on a dose of $8 \mathrm{mg} /$ day, which was increased to $16 \mathrm{mg}$ /day after four weeks of treatment, aiming at a further dose increase to $24 \mathrm{mg} /$ day. In some cases, the dose was reduced because of the presence of side effects. All decisions regarding dosage were left to the individual clinician, as in routine clinical practice, and all dosage adjustments were recorded throughout the study. The patients paid for their medication in accordance with the standards of the Swedish health care system.

\section{Dropout}

Each center recorded the dates of dropout. The reasons for dropout were investigated and included admission to a nursing home, switch to another ChEI, death, withdrawal of informed consent, reconsideration of the diagnosis, presence of side effects, compliance problems, 
poor effect/deterioration, somatic disease unrelated to galantamine treatment, addon of memantine, entering another treatment study, and other reasons.

Predictors of dropout were investigated and included age, gender, duration of illness, number of years of education, $A P O E$ genotype (presence or absence of the $A P O E 4$ allele), number of medications at baseline, type of medication at baseline, galantamine dose, and baseline MMSE, ADAScog, and IADL scores.

\section{Statistical analysis}

The SPSS program, version 17.0 (SPSS Inc, Chicago, IL) was used to perform the statistical analyses. The level of significance was set at $P<0.05$ if not otherwise specified. Nonparametric methods were used to avoid the possibility of skewed distributions. The Mann-Whitney $U$ test was applied if two independent groups were compared. The $\chi^{2}$ test was used to analyze nominal scale variables, eg, gender and APOE genotype.

The Wilcoxon signed-rank test was used to investigate differences in scores from the baseline to each assessment point. A logistic regression analysis using dropout (no/yes) as the dependent variable was applied to investigate predictors of discontinuation and their odds ratios.

A hierarchical cluster analysis using Ward's method with squared Euclidean distance was applied to determine the adequate number of clusters. Agglomeration coefficients and dendrogram analysis displayed a two-cluster solution as the most optimal. Subsequently, a k-means cluster analysis with two clusters was applied using the baseline values of IADL, ADAS-cog, the six-month IADL scale, and ADAScog change from baseline as independent variables in the analysis.

\section{Results Subjects}

The baseline characteristics of the 280 patients are displayed in Table 1 . The mean age was $73.1 \pm 8.2$ years, and $62 \%$ of the patients were female. The median level of education was $9.8 \pm 3.8$ years. The mean duration of disease was $3.0 \pm 1.7$ years. At baseline, the mean MMSE score was $23.2 \pm 4.1$ and the ADAS-cog score was $16.8 \pm 8.7$. The mean baseline IADL score was $12.8 \pm 5.2$.

At baseline, $85 \%$ of the patients had concomitant medication (Table 1). The number of medications per person was $3.0 \pm 2.7$. The six groups of medication used by more than $10 \%$ of the study population are displayed in Table 1. The largest groups of medication were to treat vascular risk
Table I Baseline characteristics and medication

\begin{tabular}{ll}
\hline & Mean \pm SD \\
\hline Patients (n) & 280 \\
Males/females \% & $38 / 62$ \\
Living status (\%) & \\
Living alone & 32 \\
Living with family & 68 \\
Age at onset, years (range) & $70.1 \pm 8.5(43-87)$ \\
Age at baseline, years (range) & $73.1 \pm 8.2(47-88)$ \\
Illness duration at baseline, years & $3.0 \pm 1.7$ \\
Years of education (range) & $9.8 \pm 3.8(7-20)$ \\
APOE E4 allele, carrier/noncarrier, $n$ (\%) & $29 / 71(274)$ \\
MMSE & $23.2 \pm 4.1(280)$ \\
ADAS-cog (0-70), mean (n) & $16.8 \pm 8.7(277)$ \\
IADL (n) & $12.8 \pm 5.2(263)$ \\
PSMS (range) & $7.0 \pm 2.0$ \\
FAST (range) & $3.4 \pm 1.3$ \\
Preprogression rate, MMSE decline/year & $3.2 \pm 3.1$ \\
Medication ${ }^{\mathrm{a}} \mathrm{n}$ (\%) & \\
Any & $236(85)$ \\
Antihypertensives/cardiac therapy & $105(38)$ \\
Vitamins (folic acid, cobalamin) & $89(32)$ \\
Acetylsalicylic acid & $8 \mathrm{I}(29)$ \\
Antidepressants & $76(27)$ \\
Lipid-lowering agents & $50(18)$ \\
Anxiolytics & $35(13)$ \\
\hline Note: &
\end{tabular}

Note: ${ }^{2}$ All baseline medications taken by more than $10 \%$ of the study population $(n=278)$, two patients did not provide baseline medication data.

Abbreviations: ADAS-cog, the Alzheimer's Disease Assessment Scale-cognitive subscale; IADL, Instrumental Activities of Daily Living; SATS, Swedish Alzheimer Treatment Study; MMSE, Mini-Mental State Examination; SD, standard deviation; FAST, Functional Assessment Staging of Alzheimer's Disease; PSMS, Physical SelfMaintenance Scale.

factors and included antihypertensive or cardiac therapy (38\%), vitamins (B12 and/or folic acid, 32\%), acetylsalicylic acid (29\%), and lipid-lowering agents (18\%). Medications for psychiatric symptoms included antidepressants (27\%) and anxiolytics (13\%). In addition 5\%-9\% of the patients used antidiabetic agents, analgesics (other than acetylsalicylic acid and nonsteroidal anti-inflammatory drugs), thyroid hormone therapy, and antacids and acid reducers. Less than $5 \%$ of the patients used antipsychotics, estrogen, nonsteroidal anti-inflammatory drugs, gingko/vitamin E, or asthma medication.

\section{Study outcomes}

Mini-Mental State Examination

The mean MMSE scores and the mean changes from baseline at the different visits are shown in Table 2. The mean MMSE score was $23.2 \pm 4.1$ at baseline and 21.7 \pm 5.7 after 36 months. The MMSE score was significantly better at two months $(P<0.001)$ and at six months $(P=0.006)$ compared with baseline, and was stable at 12 months $(P=0.616)$ 


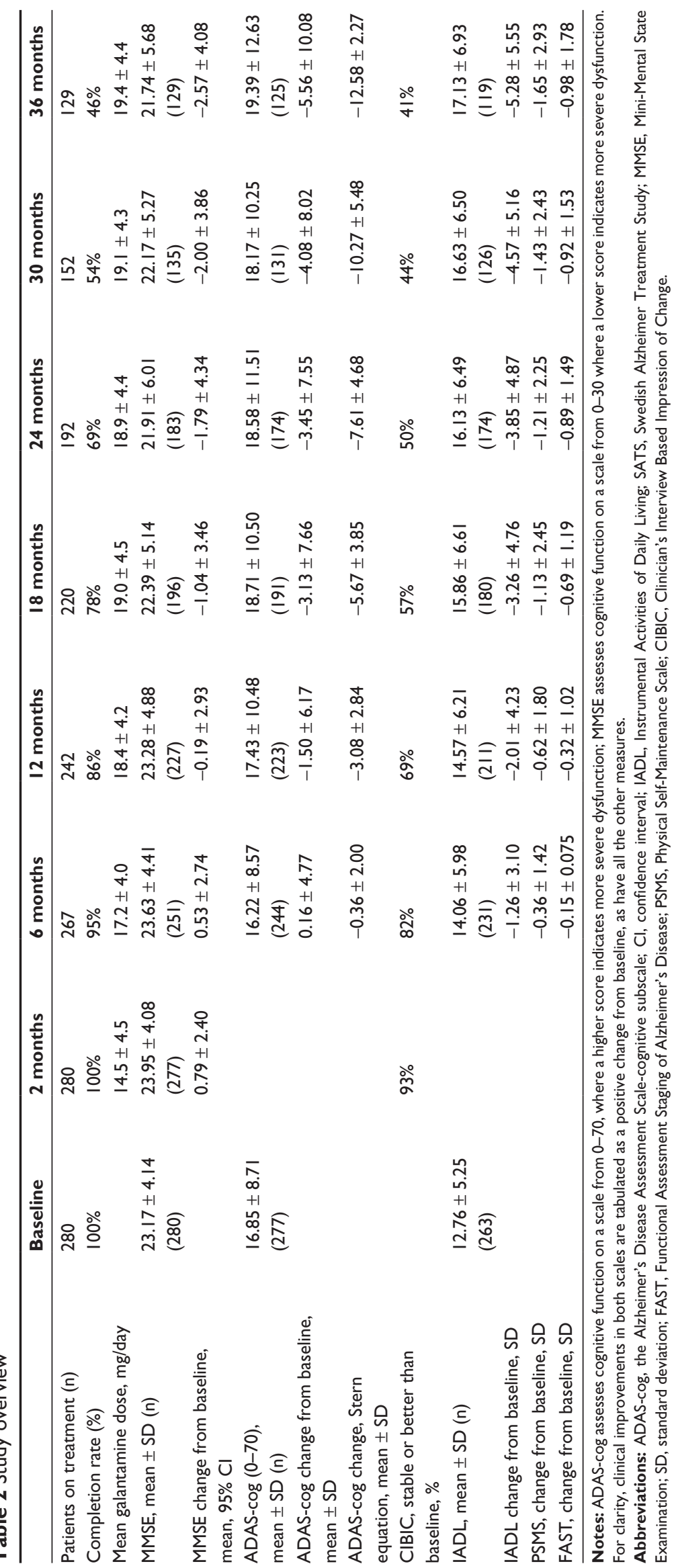


compared with baseline (Wilcoxon signed-rank test). However, it deteriorated after this time point. The MMSE changes from baseline over time are depicted in Figure 1 and Table 2. The total mean decline in MMSE score from baseline after three years of treatment was $2.6 \pm 4$.1. This three-year result was in accordance with the results described previously for one year (2-4-point change) in historical cohorts of untreated patients. ${ }^{32,35,36}$

\section{Alzheimer's Disease Assessment Scale-cognitive subscale}

The mean ADAS-cog scores and their mean changes from baseline are presented in Table 2. The mean ADAS-cog (0-70) score was $16.8 \pm 8.7$ at baseline and 19.4 \pm 12.6 after 36 months of treatment. The ADAS-cog (0-70) changes from baseline over time are described in Figure 2. The total change in ADAS-cog score after three years of treatment was $5.6 \pm 10.1$ points above the baseline values. This was significantly better than the expected change in ADAS-cog of $12.6 \pm 6.2$, as calculated using the Stern equation (Table 2 and Figure 2). Furthermore, it was better than the expected annual decline of 4-8 points recorded in untreated historical cohorts. ${ }^{30,37}$ The ADAS-cog scores at six months were not different from those recorded at the baseline (stable, $P=0.248$, Wilcoxon signed-rank test), but deteriorated after that. ADAS-cog responses at all time intervals (which were defined as "improved", 4 or more points improvement; "unchanged", 3 to -3 points of variation; and "worse", 4 points or more of deterioration) are displayed in Figure 3B.

\section{Instrumental Activities of Daily Living}

Mean IADL scores and their changes from the baseline are presented in Table 2. The IADL scores deteriorated compared with baseline at all time points (Wilcoxon signed-rank test).

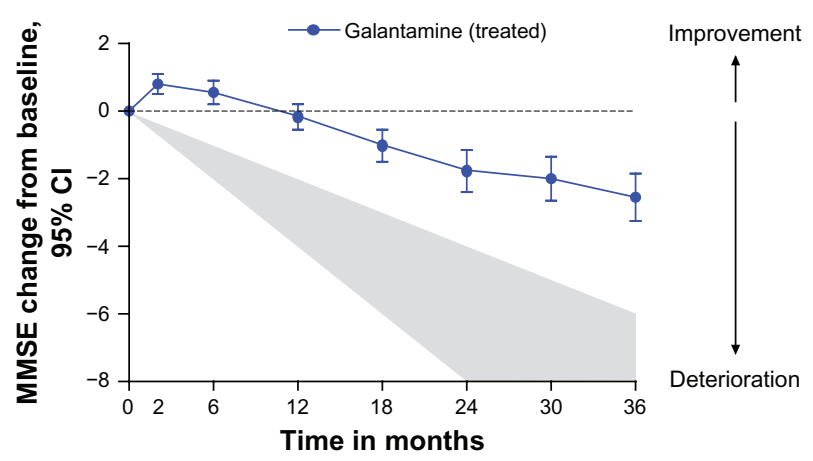

Figure I Mean changes in score from baseline ( $95 \%$ confidence interval) in galantamine-treated patients. The shaded area is an estimated annual deterioration of 2-4 points per year as described in historical cohorts of untreated patients. Abbreviation: MMSE, Mini-Mental State Examination.

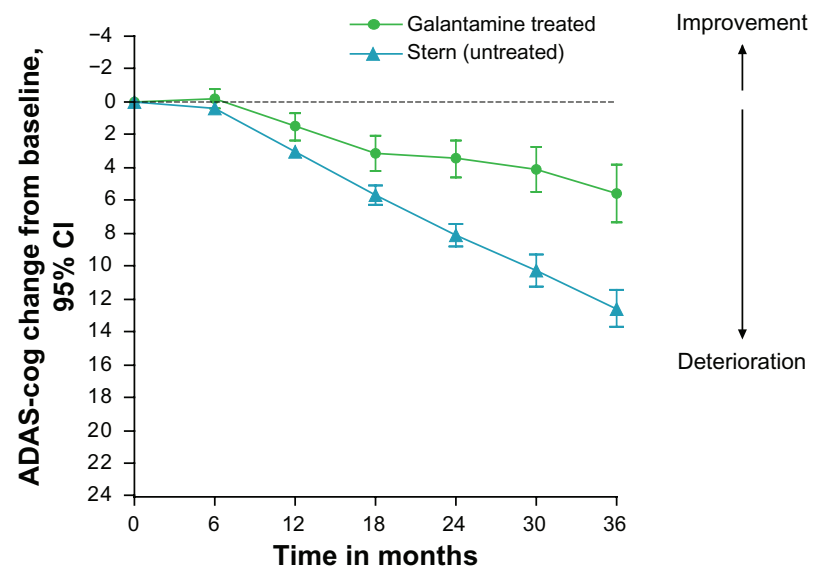

Figure 2 Mean changes in ADAS-cog score from the baseline $(95 \% \mathrm{Cl})$ in galantaminetreated patients. They were significantly better compared with the predicted change for untreated patients, calculated using the Stern equation $(95 \% \mathrm{Cl})$, from 12 months and onwards.

Abbreviations: ADAS-cog, Alzheimer's Disease Assessment Scale-cognitive subscale; $\mathrm{Cl}$, confidence interval

\section{Clinician's Interview Based Impression of Change}

The mean CIBIC scores are displayed in Table 2. In summary, three groups were defined based on the CIBIC ratings. A CIBIC score of 1-3 was considered as "improved", a CIBIC score of 4 was considered "unchanged", and a CIBIC score of $5-7$ as "worse". At two months, $93 \%$ of the patients remaining in the study were "improved or unchanged" at months $6,12,24$, and $36,81 \%, 69 \%, 50 \%$ and $41 \%$ of the patients were "improved or unchanged", respectively (Figure 3A).

\section{Subgroup analysis}

A dendrogram hierarchical cluster analysis (Ward's method) suggested a two-cluster solution. Cluster 1 was composed of 76 patients with a baseline IADL level of $16.9 \pm 5.3$ points, an ADAS-cog score of $25.9 \pm 6.5$ points, and a six-month ADAS-cog improvement from baseline of $2.0 \pm 5.5$ points. Cluster 2 was composed of 147 patients with a baseline IADL level of $10.3 \pm 3.4$ points, an ADAS-cog score of $11.4 \pm 4.0$ points, and a six-month ADAS-cog deterioration from baseline of $0.77 \pm 4.2$ points (Table 3). Patients in cluster 1 were significantly older at baseline $(P=0.002)$ and at onset $(P=0.003)$ had a worse MMSE level at baseline $(P<0.001)$, exhibited a faster pretreatment progression rate $(P<0.001)$, and were more prone to dropout from the study $(P<0.001)$ than the patients in cluster 2 . Patients in cluster 2 had a higher frequency of the $A P O E \varepsilon 4$ allele $(P=0.027)$ and a higher level of education $(P=0.007)$ than the patients in cluster 1 . The patients in the two clusters did not differ regarding gender, dose of galantamine, number of medications at baseline, or disease duration (Table 3). 
A

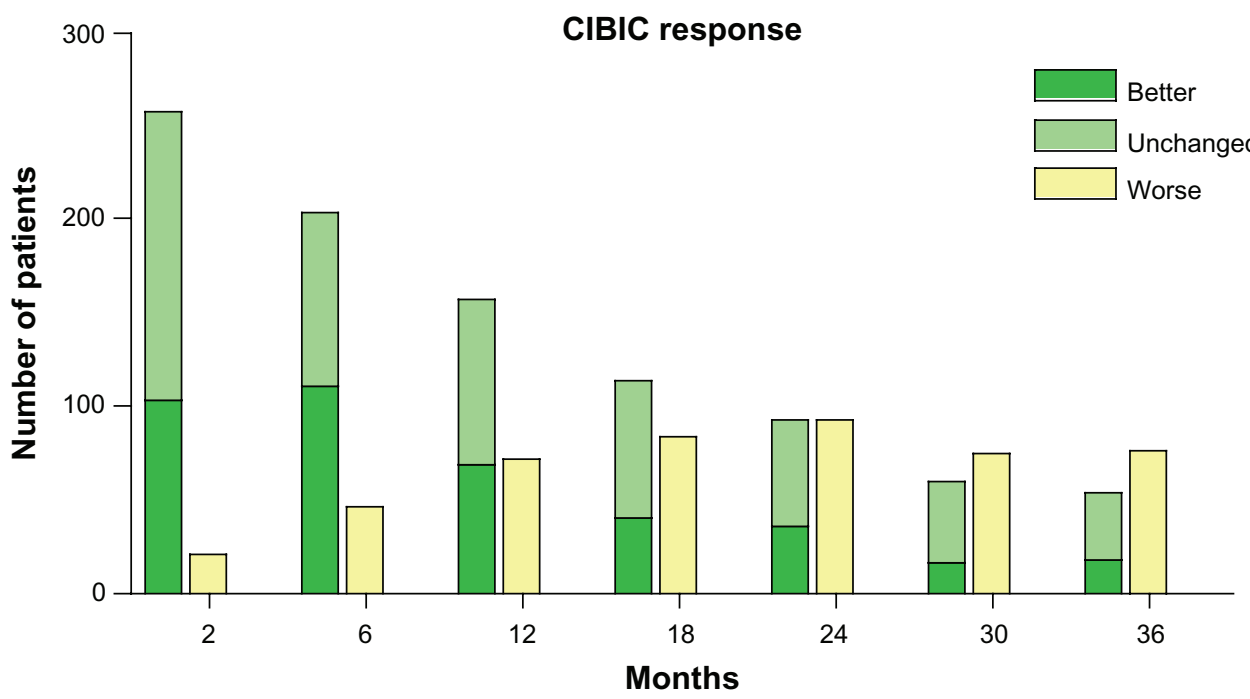

\begin{tabular}{|l|c|c|c|c|c|c|c|}
\hline CIBIC & 2 months & 6 months & 12 months & 18 months & 24 months & 30 months & 36 months \\
\hline Better, (\%) & 37 & 44 & 30 & 20 & 19 & 12 & 14 \\
\hline Unchanged, (\%) & 56 & 37 & 39 & 37 & 31 & 33 & 27 \\
\hline Worse, (\%) & 7 & 19 & 31 & 43 & 50 & 57 & 59 \\
\hline
\end{tabular}

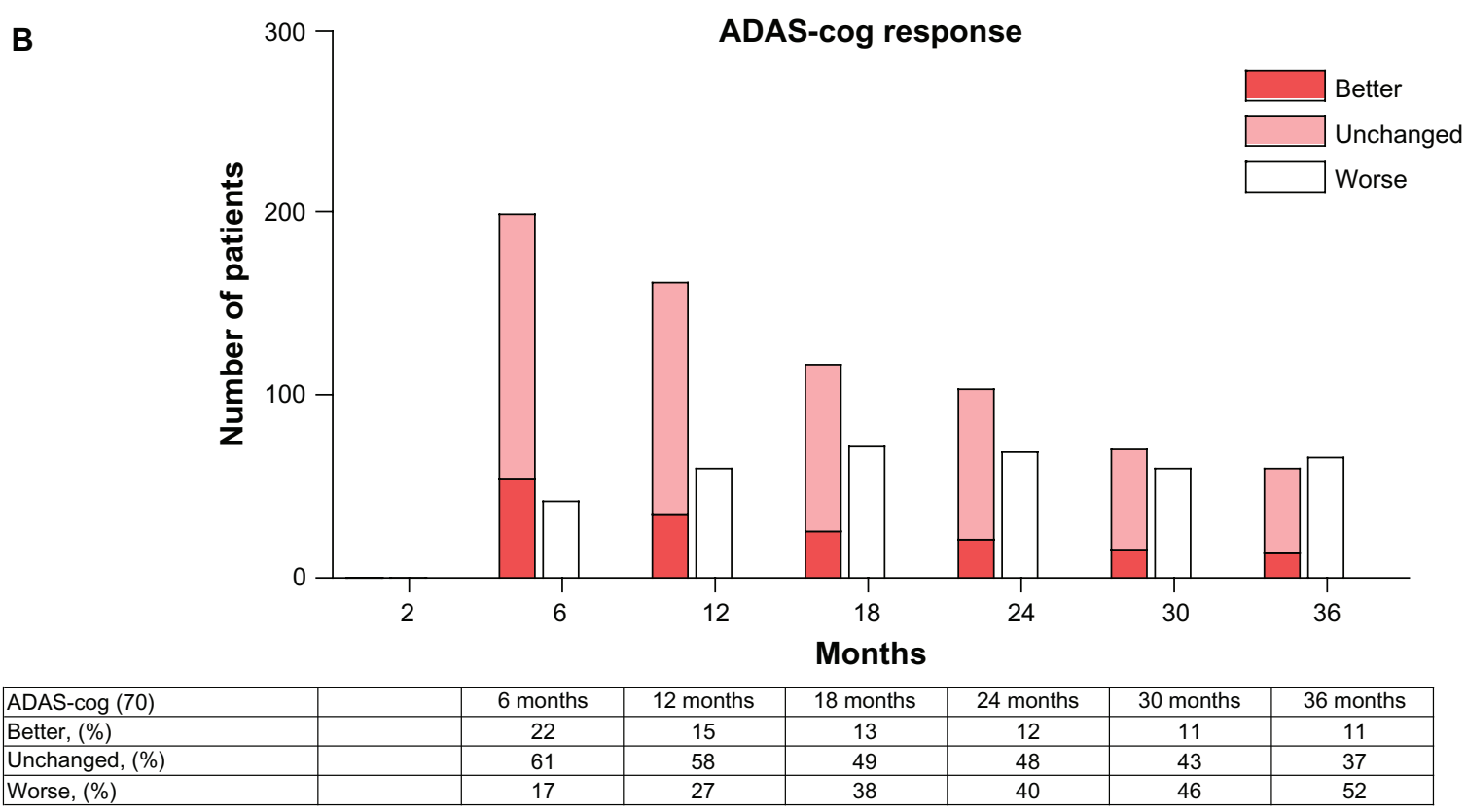

Figure 3 Global rating (CIBIC) was at all intervals compared with baseline. "Improved" was defined as a CIBIC score of I-3, "unchanged" was defined as a CIBIC score of 4 , and "worse" was defined as a CIBIC of 5-7. ADAS-cog responses at all time intervals. "Improved" was defined as 4 or more points improvement, "unchanged" was defined as 3 to -3 points of variation, and "worse" was defined as 4 points or more of deterioration.

Abbreviations: CIBIC, Clinician's Interview Based Impression of Change; ADAS-cog, Alzheimer's Disease Assessment Scale-cognitive subscale.

Patients in cluster 2 received significantly more lipidlowering medication than patients in cluster $1(P=0.019)$; otherwise, the type of medication did not differ between the two clusters (Table 3).

Patients not included in the cluster analyses because of missing data $(n=59)$ were treated with a lower dose of galantamine $(14.1 \pm 4.1 \mathrm{mg})$ compared with the patients who provided data for the cluster analysis $(16.0 \pm 3.1 \mathrm{mg})$.
However, they did not differ from the patients included in the cluster analyses regarding any of the other aspects mentioned above.

\section{Treatment}

The mean dose of galantamine was $15.6 \pm 3.4 \mathrm{mg}$, and the mean doses of galantamine administered at the different time points are displayed in Table 2 . 
Table 3 Characteristics of clusters

\begin{tabular}{|c|c|c|c|}
\hline Characteristics & $\begin{array}{l}\text { Cluster I } \\
(n=76)\end{array}$ & $\begin{array}{l}\text { Cluster } 2 \\
(n=147)\end{array}$ & $\begin{array}{l}P \text { value } \\
\text { (Mann- } \\
\text { Whitney) }\end{array}$ \\
\hline ADAS-cog (70), mean \pm SD & $25.9 \pm 6.5$ & $\mathrm{II} .4 \pm 4.0$ & $<0.001$ \\
\hline$I A D L$, mean $\pm S D$ & $16.9 \pm 5.3$ & $10.3 \pm 3.4$ & $<0.001$ \\
\hline $\begin{array}{l}\text { ADAS-cog change at } \\
6 \text { months, mean } \pm \text { SD }\end{array}$ & $2.0 \pm 5.5$ & $-0.8 \pm 4.2$ & $<0.001$ \\
\hline IADL change 6 months & $-1.5 \pm 3.4$ & $-1.0 \pm 2.7$ & 0.233 \\
\hline Age at onset, mean \pm SD & $72.3 \pm 8.6$ & $68.8 \pm 8.5$ & 0.003 \\
\hline Age at baseline, mean \pm SD & $75.4 \pm 8.2$ & $71.8 \pm 8.1$ & 0.002 \\
\hline $\begin{array}{l}\text { Duration of disease } \\
\text { at baseline }\end{array}$ & $2.9 \pm 1.8$ & $3.0 \pm 1.8$ & 0.635 \\
\hline Female gender, \% & 64 & 60 & $0.491^{\mathrm{a}}$ \\
\hline $\begin{array}{l}\text { MMSE at baseline, } \\
\text { mean } \pm \text { SD }\end{array}$ & $19.4 \pm 3.1$ & $25.3 \pm 2.8$ & $<0.001$ \\
\hline Dropouts during study (\%) & 71 & 39 & $<0.00 \mathrm{I}^{\mathrm{a}}$ \\
\hline APOE ع4 allele carrier (\%) & 62 & 76 & $0.027^{\mathrm{a}}$ \\
\hline $\begin{array}{l}\text { Galantamine dose, } \mathrm{mg}, \\
\text { mean } \pm \mathrm{SD}\end{array}$ & $16.2 \pm 3.0$ & $15.7 \pm 3.4$ & 0.311 \\
\hline Education, years & $8.8 \pm 3.1$ & $10.3 \pm 4.0$ & 0.007 \\
\hline Medications (n) & $2.7 \pm 2.6$ & $3.1 \pm 2.8$ & 0.305 \\
\hline $\begin{array}{l}\text { Preprogression rate, } \\
\text { MMSE decline/year }\end{array}$ & $5.2 \pm 3.5$ & $2.3 \pm 2.3$ & 0.001 \\
\hline
\end{tabular}

Notes: For clarity, clinical improvements in both scales is tabulated as a positive change from baseline as have all the other measures. ${ }^{a} \mathrm{Chi}$-square.

Abbreviations: ADAS-cog, the Alzheimer's Disease Assessment Scale-cognitive subscale; IADL, Instrumental Activities of Daily Living; SATS, Swedish Alzheimer Treatment Study; MMSE, Mini-Mental State Examination; SD, standard deviation.

\section{Dropout}

Completion rates are displayed in Table 2. The reasons for dropout are described in Table 4. The three most common causes of dropout were not associated with stopping galantamine treatment. Twenty-five percent of the patients left the study when memantine was added to the galantamine treatment. Another $15 \%$ of the patients left the study because they were recruited to other studies, eg, vaccination programs. In addition, $13 \%$ left the study at the time they moved to a nursing home but continued galantamine treatment. However, moving to a nursing home was not an

Table 4 Study dropouts

\begin{tabular}{ll}
\hline Direct reason for dropout, total $(\mathrm{n})$ & $15 \mathrm{I}$ \\
Adding memantine & 37 \\
Taking part in another study & 23 \\
Admission to nursing home & 19 \\
Side effects & 14 \\
Deterioration & 11 \\
Compliance problems & 10 \\
Death & 10 \\
Withdrawal of informed consent & 10 \\
Other reason & 13 \\
Missing & 4 \\
\hline
\end{tabular}

end point of the study. Twenty-three patients continued in the Swedish Alzheimer Treatment Study after nursing home placement and contributed data to the study.

The baseline characteristics of the completers and noncompleters of the present study were compared. Patients who left the study during the three-year interval had a significantly higher baseline ADAS-cog score $(P<0.001)$, a lower MMSE score $(P<0.001)$, and a higher IADL score $(P<0.001)$ compared with patients who remained in the study, thus indicating a more severe disease level. Moreover, the mean galantamine dose administered to noncompleters was lower $(16.5 \pm 4.6 \mathrm{mg})$ compared with that administered to completers $(18.0 \pm 3.1 \mathrm{mg} ; P<0.004)$. The dropouts did not differ in number of medications at baseline, age at onset, age at baseline, duration of illness, education in years, gender, or $A P O E$ genotype compared with patients who completed the three years of the study. No differences in medication profiles at baseline were observed regarding use of any of the medication groups between the dropouts and completers. Similar results were obtained using a logistic regression model. A higher MMSE score at baseline $(P<0.001$; odds ratio, 0.857$)$ reduced the risk of dropout by $14.3 \%$ per MMSE point increase. Moreover, a higher dose of galantamine $(P<0.001$; odds ratio, 0.81$)$ reduced the risk of discontinuation by $19 \%$ for every milligram increase in galantamine dose. However, age, IADL at baseline, $A P O E$ genotype, years of education, and number of medications did not influence dropout.

\section{Discussion}

AD patients treated with galantamine in a routine clinical setting exhibited cognitive stabilization for up to one year after the onset of treatment. After three years of treatment, the mean MMSE change from baseline was 2.6 points. Subgroup response was assessed using cluster analyses, and two stable clusters were identified. Patients with higher age, lower cognitive and functional ability at baseline, faster pretreatment progression rate, and lower frequency of the $A P O E \& 4$ allele exhibited a better short-term response to treatment, but dropped out earlier. Moreover, a high adherence to treatment was observed compared with that reported by earlier studies, and the three-year completers received higher galantamine doses than the noncompleters.

The routine clinical setting, which renders our results relevant also for the "ordinary" AD patient, was one of the advantages of the present study. This is especially important because the highly selected cohorts used in placebo-controlled 
trials may not be representative of patients in a real clinical setting. ${ }^{38}$ Moreover, even though we used a clinical routine setting, the data were collected prospectively and the evaluation was structured and standardized.

One of the limitations of long-term AD studies is the absence of a control group, which is not possible to obtain for ethical reasons. Because long-term, placebo-controlled studies in AD are limited in time to a duration of six months, the analysis of long-term outcome is limited to open-label studies. Because AD is a disease with a duration of decades, these open follow-up investigations are important.

The present study showed that mean MMSE levels in AD patients were improved over six months and were stable for up to one year after the onset of treatment. Stabilization over one year has been described previously in cohorts of galantamine-treated patients. ${ }^{39}$ The expected annual decline in MMSE score described previously was 2-4 points in nontreated historical cohorts ${ }^{32,35,36}$ and 2.2 points in placebotreated patients. ${ }^{33}$ In the present study, the mean change in MMSE score from the baseline was 2.6 points, after not one but three years of treatment.

Moreover, the three-year deterioration in ADAS-cog score was 5.6 points compared with the one-year deterioration of 8 points described in older untreated $\mathrm{AD}$ cohorts ${ }^{30,31}$ and the 18-month deterioration of 6.7 points observed in a more recent study of a cohort with milder AD. ${ }^{40}$ The consistency between the outcomes obtained using two different scales strengthens these results. However, comparison of the outcomes of our study with those observed in previous placebo-controlled cohorts or earlier long-term studies must be performed with caution. Differences in cohorts, level of disease, and study design can influence the outcome. In an earlier analysis of Swedish Alzheimer Treatment Study data stemming from a donepezil-treated cohort, our group demonstrated a decline in MMSE score of 3.8 points after three years of treatment. ${ }^{21}$ Because that cohort was, on average, older and more cognitively impaired at treatment onset compared with the patients presented in the current study, the comparison of these results remains difficult, but will be obtained by our group in the future using statistical methods such as mixed models.

In the study presented here, $69 \%$ of the patients were globally assessed as "improved or unchanged" at one year, $50 \%$ were "improved or unchanged" at two years, and $41 \%$ were "improved or unchanged" at three years. This result was better than that observed in an earlier three-year follow-up study of donepezil-treated patients $(49 \%, 35 \%$, and $30 \%$, respectively), ${ }^{21}$ as well as that observed in nontreated cohorts $\left(34 \%, 13 \%, 14 \%\right.$, respectively). ${ }^{17}$
The response to ChEI treatment varies among the AD population. AD is a heterogeneous condition, and it is likely that the efficacy of various therapies differs among subgroups. This can depend not only on the medication used, but also on factors influencing disease progression ("how fast") or disease severity ("how far"). Severity of disease and fast progression rate predict a positive shortterm response to ChEI treatment in $\mathrm{AD} .{ }^{41,42}$ However, the existence of malignant forms of $\mathrm{AD}$ with a fast progression rate and a lack of short-term response to ChEI treatment has also been reported. ${ }^{43}$ The definition of treatment response therefore remains difficult. There are no standard guidelines to describe response to treatment, and different definitions of response have been used previously..$^{10}$ To overcome these difficulties in response definition, data-driven techniques, such as cluster analysis, may be better suited to the investigation of natural subgroups in AD treatment studies. Rockwood et al applied a cluster analysis to define outcome groups among a three-year completer population of $\mathrm{AD}$ patients. ${ }^{44}$ In the study presented here, we included not only the completer population, but all patients who provided at least six months of data. A stable two-cluster model was obtained, with different responses and characteristics. In our model, the response defined by the cluster analysis showed that patients exhibiting a better response at six months (cluster 1, $\mathrm{n}=76$ ) had lower baseline ADAS-cog and IADL scores and a faster pretreatment progression rate, which was in line with earlier observations using other response definitions. The calculated estimation of pretreatment progression rate ${ }^{34}$ yielded the same predictive response (faster pretreatment progression/better short-term response) as that described in earlier cohorts for which pretreatment progression rate was measured, rather than being calculated. ${ }^{42}$

Analysis of the differences between dropouts and completers of the present study showed that the three-year completers had less advanced disease at baseline and received higher doses of galantamine than the noncompleters. Low doses of ChEIs have been associated with early discontinuation $^{45}$ and some studies showed that higher ChEI doses enhance short-term response. ${ }^{46}$ These results stress the importance of using adequate $\mathrm{ChEI}$ doses in $\mathrm{AD}$ treatment to enhance adherence and response to treatment. Patients in cluster 2 dropped out to a lesser extent than patients in cluster 1 . However, these two clusters did not differ in galantamine dose, but patients in cluster 2 were treated with lipid-lowering medication at baseline to a greater extent than patients in cluster 1. A protective effect of this medication cannot be ruled out, but this remains to be explored further using larger cohorts. 
In our cohort, $27 \%$ of patients were medicated with antidepressants at baseline, ie, before inclusion in the study. This figure is not high in naturalistic cohorts, because several studies show that AD patients have a large comorbidity with depression, ranging from $20 \%$ to $30 \%$. Among large European naturalistic AD cohorts, a 24\% depression rate was described in one study ${ }^{47}$ and in another study antidepressants were prescribed to $34 \%$ of the patients. ${ }^{48} \mathrm{We}$ know that the patients receiving antidepressants at baseline did not drop out to a greater extent than the ones without this treatment.

High dropout rates are a problem in all long-term AD studies. Appendix 1 provides an overview of dropouts in various long-term studies to highlight this issue. Three-year completion rates of $4 \%-39 \%$ are reported. Thus, the three-year completion rate of $46 \%$ obtained in the current study is high compared with that of other long-term AD studies. In the present study, the two major reasons for dropout were addition of memantine or recruitment of patients to other treatment studies. As new treatment options emerged, patients were free to leave the present study to try other options. We do not know at this point whether these patients would have contributed to a different outcome if they had remained in the present study for the three-year period. We know that they were younger and better educated (data not shown), but did not differ in MMSE or ADAS-cog scores at baseline from the other dropout groups (data not shown). However, the possibility that patient deterioration was one of the reasons for adding memantine cannot be ruled out.

A recent observational health database study revealed that only $54 \%$ of patients receiving galantamine continued to do so for one year, ${ }^{49}$ which was longer than that observed for the donepezil-treated and rivastigmine-treated patients included in the same survey. Enhancement of the completion rates in long-term $\mathrm{AD}$ studies will be crucial in future studies of protective treatments, because these must be performed on a long-term basis.

\section{Conclusion}

Long-term galantamine treatment in a routine clinical setting resulted in stabilization of cognitive and global decline in AD patients. Moreover, after two years of treatment, half of the patients showed cognitive and global stabilization of their condition. We identified subgroups of patients with differential responses to treatment and dropout. The Swedish Alzheimer Treatment Study protocol used in this clinical setting may have contributed to the high completion rates observed in this study.

\section{Acknowledgments}

These data are presented on behalf of the Swedish Alzheimer Treatment Study Group steering committee, the members of which are outlined in Appendix 2. We wish to thank all the patients and their relatives who participated in this study. The authors are grateful to Daniel Ehinger for secretarial work, and to our research nurses, Cecilia Dahl, Annacarin Björkman, Yvonne Sjöberg, Tarja Tikkanen, and Eva Falk Langebro. We also wish to thank the staff of the different centers who participated in the management of the patients included in the study. This work was supported by grants from the Alzheimer Foundation, Sweden. Independent grants were received from Janssen-Cilag.

\section{Disclosure}

AKW has received speaker honoraria from Janssen-Cilag. $\mathrm{CW}$ has no disclosures to report. LM is a member of the advisory board at Pfizer AB, Sweden, and has received speaker honoraria from Pfizer.

\section{References}

1. Fratiglioni L, Launer LJ, Andersen K, et al. Incidence of dementia and major subtypes in Europe: A collaborative study of population-based cohorts. Neurology. 2000;54 Suppl 5:10-15.

2. Fratiglioni L, De Ronchi D, Agüero-Torres H. Worldwide prevalence and incidence of dementia. Drugs Aging. 1999;15:365-375.

3. Christensen K, Doblhammer G, Rau R, Vaupel JW. Ageing populations: the challenges ahead. Lancet. 2009;374:1196-1208.

4. Galasko D, Edland SD, Morris JC, Clark C, Mohs R, Koss E. The Consortium to Establish a Registry for Alzheimer's Disease (CERAD): Part XI. Clinical milestones in patients with Alzheimer's disease followed over 3 years. Neurology. 1995;45:1451-1455.

5. Burns A, O'Brien J, Auriacombe S, et al; on behalf of the BAP Dementia Consensus Group. Clinical practice with anti-dementia drugs: a consensus statement from British Association for Psychopharmacology. J Psychopharmacol. 2006;20:732-755.

6. Samochocki M, Zerlin M, Jostock R, et al. Galantamine is an allosterically potentiating ligand of the human alpha4/beta2 nAChR. Acta Neurol Scand Suppl. 2000;176:73.

7. Loy C, Schneider L. Galantamine for Alzheimer's disease and mild cognitive impairment. Cochrane Database Syst Rev. 2006;1:CD001747.

8. Tariot PN, Solomon PR, Morris JC, Kershaw P, Lilienfeld S, Ding C. A 5-month, randomized, placebo-controlled trial of galantamine in AD. The Galantamine USA-10 Study Group. Neurology. 2000;5: 2269-2276.

9. Raskind MA, Peskind ER, Wessel T, Yuan W. Galantamine in AD: A 6-month randomized, placebo-controlled trial with a 6-month extension. The Galantamine USA-1 Study Group. Neurology. 2000;54:2261-2268.

10. Lanctôt KL, Herrmann N, LouLou MM. Correlates of response to acetylcholinesterase inhibitor therapy in Alzheimer's disease. J Psychiatry Neurosci. 2003;28:13-26.

11. Rockwood K, Fay S, Gorman M, Carver D, Graham J. The clinical meaningfulness of ADAS-cog changes in Alzheimer's disease patients treated with donepezil in an open-label trial. BMC Neurology. 2007;7:26.

12. Courtney C, Farrell D, Gray R, et al. Long-term donepezil treatment in 565 patients with Alzheimer's disease (AD2000): Randomised doubleblind trial. Lancet. 2004;363:2105-2115. 
13. Winblad B, Wimo A, Engedal K, et al. 3-year study of donepezil therapy in Alzheimer's disease: Effects of early and continuous therapy. Dement Geriatr Cogn Disord. 2006;21:353-363.

14. Small GW, Kaufer D, Mendiondo MS, Quarg P, Spiegel R. Cognitive performance in Alzheimer's disease patients receiving rivastigmine for up to 5 years. Int $J$ Clin Pract. 2005;59:473-477.

15. Pirtilla T, Wilcock G, Truyen L, Damaraju CV. Long-term efficacy and safety of galantamine in patients with mild-to-moderate Alzheimer's disease: multicenter trial. Eur J Neurol. 2004;11:734-741.

16. Rogers SL, Doody RS, Pratt RD, Ieni JR. Long-term efficacy and safety of donepezil in the treatment of Alzheimer's disease: final analysis of a US multicentre open-label study. Eur Neuropsychopharmacol. 2000;10: 195-203.

17. Holmes $\mathrm{C}$, Lovestone S. Long-term cognitive and functional decline in late onset Alzheimer's disease: therapeutic implications. Age Aging 2003;32:200-204.

18. Lyle S, Grizzell M, Willmott S, Benbow S, Clark M, Jolley D. Treatment of a whole population sample of Alzheimer's disease with donepezil over a 4-year period: lessons learned. Dement Geriatr Cogn Disord. 2008;25:226-231.

19. Wallin $\AA$ K, Gustafson L, Sjogren M, Wattmo C, Minthon L. Five-year outcome of cholinergic treatment of Alzheimer's disease: Early response predicts prolonged time until nursing home placement, but does not alter life expectancy. Dement Geriatr Cogn Disord. 2004;18:197-206.

20. Minthon L, Wallin ÅK, Eriksson S, Wattmo C, Andreasen N. Long-term rivastigmine treatment in a routine clinical setting. Acta Neurol Scand. 2009;119:180-185.

21. Wallin ÅK, Andreasen N, Eriksson S, et al. Donepezil in Alzheimer's disease: What to expect after 3 years of treatment in a routine clinical setting. Dement Geriatr Cogn Disord. 2007;23:150-160.

22. American Psychiatric Association. American Psychiatry Association: Diagnostic and Statistical Manual of Mental Disorders, 4th Edition. Washington, DC: American Psychiatric Association; 1994.

23. McKhann G, Drachman D, Folstein M, Katzman R, Price D, Stadlan EM. Clinical diagnosis of Alzheimer's disease: Report of the NINCDS-ADRDA Work Group under the auspices of Department of Health and Human Services Task Force on Alzheimer's Disease. Neurology. 1984;34:939-944.

24. Folstein MF, Folstein S, McHugh PR. "Mini-Mental state": a practical method for grading the cognitive state of patients for the clinician. J Psychiatry Res. 1975;12:189-198.

25. Rosen WG, Mohs RC, Davis KL. A new rating scale for Alzheimer's disease. Am J Psychiatry. 1984;141:1356-1364.

26. Lawton MP, Brody EM. Assessment of older people: Self-maintaining and instrumental activities of daily living. Gerontologist. 1969;9:179-186.

27. Knapp MJ, Knopman DS, Solomon PR, et al. A 30-week randomized controlled trial of high-dose tacrine in patients with Alzheimer's disease. JAMA. 1994;271:985-991.

28. Schneider LS, Olin JT. Clinical global impressions in Alzheimer's clinical trials. Int Psychogeriatr. 1996;8:277-288.

29. Knopman DS, Knapp MJ, Gracon SI, Davis CS. The Clinician Interview-Based Impression (CIBI): A clinician's global change rating scale in Alzheimer's disease. Neurology. 1994;44:2315-2321.

30. Stern R, Mohs R, Davidson M, et al. A longitudinal study of Alzheimer's disease: measurement, rate, and predictors of cognitive deterioration. Am J Psychiatry. 1994;151:390-396.

31. Yesavage JA, Poulsen AB, Sheikh J, Tanke E. Rates of change of common measures of impairment in senile dementia of the Alzheimer's type. Psychopharmacol Bull. 1988;24:531-534.

32. Han L, Cole M, Bellavance F, McCusker J, Primeau F. Tracking cognitive decline in Alzheimer's disease using the Mini-Mental State Examination: a meta-analysis. Int Psychogeriatr. 2000;12: 231-247.

33. Winblad B, Engedal K, Soininen H, et al. A 1-year, randomized, placebo-controlled study of donepezil in patients with mild to moderate AD. Neurology. 2001;57:489-495.
34. Doody R, Pavlik V, Massman P, Rountree S, Darby E, Chan W. Predicting progression of Alzheimer's disease. Alzheimers Res Ther. 2010;2:2.

35. Salmon DP, Thal LJ, Butters N, Heindel W. Longitudinal evaluation of dementia of the Alzheimer type: a comparison of 3 standardized mental status examinations. Neurology. 1990;40:1225-1230.

36. Mendiondo MS, Ashford JW, Kryscio RJ, Schmitt FA. Modelling Mini Mental State Examination changes in Alzheimer's disease. Stat Med. 2000;19:1607-1616.

37. Kramer-Ginsberg E, Mohs RC, Aryan M, et al. Clinical predictors of course for Alzheimer patients in a longitudinal study: a preliminary report. Psychopharmacol Bull. 1988;24(3):458-462.

38. Cummings JL. Use of cholinesterase inhibitors in clinical practice: evidence-based recommendations. Am J Geriatr Psychiatry. 2003;11: 131-145.

39. Wilcock G, Howe I, Coles H, et al. A long-term comparison of galantamine and donepezil in the treatment of Alzheimer's disease. Drugs Aging. 2003;20:777-789.

40. Green RC, Schneider LS, Amato DA, et al. Effect of tarenflurbil on cognitive decline and activities of daily living in patients with mild Alzheimer disease. JAMA. 2009;302:2557-2564.

41. Pakrasi S, Mukaetova-Ladinska EB, McKeith IG, O'Brien JT. Clinical predictors of response to acetyl cholinesterase inhibitors: experience from routine clinical use in Newcastle. Int J Geriatr Psychiatry. 2003;18: 879-886.

42. Farlow MR, Hake A, Messina J, Hartman R, Veach J, Anand R. Response of patients with Alzheimer disease to rivastigmine treatment is predicted by the rate of disease progression. Arch Neurol. 2001;58: $417-422$.

43. Wallin ÅK, Blennow K, Zetterberg H, Londos E, Minthon L, Hansson O. CSF biomarkers predict a more malignant outcome in Alzheimer disease. Neurology. 2010;74:1531-1537.

44. Rockwood K, Dai D, Mitnitski A. Patterns of decline and evidence of subgroups in patients with Alzheimer's disease taking galantamine for up to 48 months. Int J Geriatr Psychiatry. 2008;23:207-214.

45. Kröger E, van Marum R, Souverein P, Egberts T. Discontinuation of cholinesterase inhibitor treatment and determinants thereof in the Netherlands: A retrospective cohort study. Drugs Aging. 2010;27: 663-675.

46. Rockwood K. Size of the treatment effect on cognition of cholinesterase inhibition in Alzheimer's disease. J Neurol Neurosurg Psychiatry. 2005;75:677-685.

47. Reynish E, Cortes F, Andrieu S, et al. The ICTUS Study: A prospective longitudinal observational study of 1,380 AD patients in Europe. Neuroepidemiology. 2007;29:29-38.

48. Arbus C, Gardette V, Bui E, et al. Antidepressant use in Alzheimer's disease patients: results of the REAL.FR cohort. Int Psychogeriatr. 2010;22:120-128.

49. Herrmann N, Binder C, Dalziel W, Smyth S, Camacho F. Persistence with cholinesterase inhibitor therapy for dementia: an observational administrative health database study. Drugs Aging. 2009;26: 403-407.

50. Doody RS, Geldmacher DS, Gordon B, et al; for the Donepezil Study Group. Open-label, multicenter, Phase 3 extension study of the safety and efficacy of donepezil in patients with Alzheimer disease. Arch Neurol. 2001;58:427-433.

51. Grossberg G, Irwin P, Satlin A, Mesenbrink P, Spiegel R. Rivastigmine in Alzheimer disease - efficacy over two years. Am J Geriatr Psychiatry. 2004;12:420-431.

52. Raschetti R, Maggini M, Sorrentino GC, Martini N, Caffari B, Vanacore N. A cohort study of effectiveness of acetylcholinesterase inhibitors in Alzheimer's disease. Eur J Clin Pharmacol. 2005;61:361-368.

53. Bullock R, Touchon J, Bergman H, et al. Rivastigmine and donepezil treatment in moderate to moderately-severe Alzheimer's disease over a 2-year period. Curr Med Res Opin. 2000;21:1317-1327.

54. Mohs RC, Doody RS, Morris JC, et al. A 1-year, placebo-controlled preservation of function survival study of donepezil in $\mathrm{AD}$ patients. Neurology. 2001;5:481-488. 


\section{Appendix I}

\section{Completion rates in long-term studies of Alzheimer's disease}

\begin{tabular}{|c|c|c|c|c|c|c|c|}
\hline & $\begin{array}{l}\text { MMSE (mean) } \\
\text { baseline level }\end{array}$ & $\begin{array}{l}\text { Baseline } \\
\text { (n) }\end{array}$ & I-year & 2-year & 3-year & 4-year & 5-year \\
\hline \multicolumn{8}{|l|}{ Randomized controlled trials } \\
\hline Mohs et $\mathrm{al}^{54}$ (don) & I7.I & 431 & $26 \%$ & & & & \\
\hline Winblad et $\mathrm{al}^{33}$ (don) & 19.4 & 286 & $67 \%$ & & & & \\
\hline Courtney et al ${ }^{12}\left(A D 2000\right.$, don) ${ }^{\mathrm{a}}$ & 19 (median) & 565 & $52 \%$ & $20 \%$ & $3.5 \%$ & & \\
\hline \multicolumn{8}{|c|}{ Randomized controlled trials with open-label extensions } \\
\hline Rogers et $\mathrm{al}^{16}(\mathrm{don})^{\mathrm{b}}$ & 27 (mean ADAS-cog) & 133 & $75 \%$ & $29 \%$ & $22 \%$ & $15 \%$ & $3 \%$ \\
\hline Doody et al ${ }^{50}(\text { don })^{\mathrm{c}}$ & (range 10-26) & 763 & $75 \%$ & $48 \%$ & $7 \%^{\mathrm{d}}$ & & \\
\hline Grossberg et al ${ }^{51}$ (riv) & 19.4 & 2010 & $74 \%$ & $48 \%$ & & & \\
\hline Pirtilla et al ${ }^{15}$ (gal) & 19.4 & 1039 & & $47 \%$ & $30 \%{ }^{\mathrm{e}}$ & & \\
\hline Small et al ${ }^{14}$ (riv) & 19.3 & 1998 & $74 \%$ & $52 \%$ & $33 \%$ & $15 \%$ & $4 \%$ \\
\hline Winblad et al ${ }^{13}$ (don) & 19.4 & 286 & $67 \%$ & $49 \%$ & $39 \%$ & & \\
\hline \multicolumn{8}{|c|}{ Open studies from naturalistic settings } \\
\hline Minthon et a ${ }^{20}$ SATS (riv) & 22.9 & 217 & $89 \%$ & $66 \%$ & & & \\
\hline Wallin et al ${ }^{21}$ SATS (don) & 22.0 & 435 & $82 \%$ & $60 \%$ & $38 \%$ & & \\
\hline Lyle et al ${ }^{18}$ (don) & 18.8 & 88 & $57 \%$ & $43 \%$ & $20 \%$ & $12 \%$ & \\
\hline Raschetti et al ${ }^{52}$ (don, riv, gal) & 18.2 & 5462 & $52 \%^{f}$ & & & & \\
\hline Wallin et al ${ }^{19}$ (tacrine) & 20.5 & 50 & $66 \%$ & $46 \%$ & $30 \%$ & $26 \%$ & $\begin{array}{l}16 \%(4 \% \\
\text { with MMSE) }\end{array}$ \\
\hline \multicolumn{8}{|l|}{ Without treatment } \\
\hline $\begin{array}{l}\text { Holmes and Lovestone }{ }^{17} \\
\text { (no treatment) }\end{array}$ & 17.0 & $|5|$ & $66 \%$ & $44 \%$ & $32 \%$ & & \\
\hline \multicolumn{8}{|l|}{ Head-to-head studies } \\
\hline Bullock et al ${ }^{53}$ (riv, don) & & 994 & & $58 \%$ & & & \\
\hline
\end{tabular}

Notes: aMultiple washout periods; ' 161 patients entered I2-week randomized controlled trial, 2 weeks washout, 133 entered open phase; ${ }^{\text {c } 3-w e e k ~ o r ~ 6-w e e k ~ w a s h o u t ~}$ periods before open-label study started; ${ }^{2} 2.8$ years; ${ }^{e} 64 \%$ of 12 -month completers, continuous 24 mg galantamine treatment; ${ }^{f}$ nine months.

Abbreviations: ADAS-cog, the Alzheimer's Disease Assessment Scale-cognitive subscale; don, donezepil; riv, rivastigmine; gal, galantamine; SATS, Swedish Alzheimer Treatment Study; MMSE, Mini-Mental State Examination.

\section{Appendix 2}

\section{The Swedish Alzheimer Treatment Study Group steering committee}

Lennart Minthon (principal investigator), Niels Andreasen, Sture Eriksson, Annacarin Björkman (study coordinators); Lennart Minthon, Åsa Wallin, Carina Wattmo, Annacarin Björkman, Cecilia Dahl, Clinical Memory Research Unit, Department of Clinical Sciences, Malmö, Lund University, Malmö; Stellan Båtsman, Anett Wunsch, Department of Primary Care, Kalix; Maria Eriksdotter Jönhagen, Niels Andreasen, Christina Sjödin, Department of Neurotec, Section Clinical Geriatrics, Karolinska Institutet, Alzheimer's Disease Research Center, Karolinska University Hospital,
Huddinge, Stockholm; Sture Eriksson, Birgitta Näsman, Liselotte Mannberg, Department of Community Medicine and Rehabilitation, Umeå University, Umeå; Michaela Grut, Marie Rydén, Eva Mohlin, Department of Geriatric Medicine, Cognitive Section, Danderyd Hospital, Danderyd; Anders Wallin, Mikael Jonsson, Kerstin Gustavsson, Institute of Clinical Neuroscience, Göteborg University, Göteborg; Hasse Olofsson, Berit Holm, Memory Clinic Uddevalla Hospital, Uddevalla; Anders Nelvig, Cathrin Viklund, Geriatric Clinic, Sundsvall Hospital, Sundsvall; Torgny Jarl, Maria Könberg, Geriatric Clinic, Härnösands Hospital, Härnösand; Kristina Are, Birgitta Liffner, Carina Borén, Department of Geriatric Falköpings Hospital, Falköping, Sweden.
Neuropsychiatric Disease and Treatment

\section{Publish your work in this journal}

Neuropsychiatric Disease and Treatment is an international, peerreviewed journal of clinical therapeutics and pharmacology focusing on concise rapid reporting of clinical or pre-clinical studies on a range of neuropsychiatric and neurological disorders. This journal is indexed on PubMed Central, the 'PsycINFO' database and CAS, and is the official

\section{Dovepress}

journal of The International Neuropsychiatric Association (INA). The manuscript management system is completely online and includes a very quick and fair peer-review system, which is all easy to use. Visit http://www.dovepress.com/testimonials.php to read real quotes from published authors. 